\section{ECOLOGICAL OBSERVATIONS ON THE INDIAN SPINY-TAILED LIZARD SAARA HARDWICKII (GRAY, 1827) (REPTILIA: SQUAMATA: AgamidaE) in TAL CHHAPAR WildLIfE SANCTUARY, RAJASTHAN, INDIA}

\section{Sanjay K. Das ${ }^{1}$, Sumit Dookia ${ }^{2}$, Kalpana Das $^{3} \&$ Sushil K. Dutta ${ }^{4}$}

1,2,3 University School of Environment Management, Guru Gobind Singh Indraprastha University, Sector-16 C, Dwarka, New Delhi 110075 India

${ }^{4}$ Centre for Ecological Sciences, New Biological Sciences Building, Indian Institute of Science, Bengaluru, Karnataka 560012, India

${ }^{1}$ skdasipu@gmail.com (corresponding author), ${ }^{2}$ sumitdookia@gmail.com, ${ }^{3}$ kkalpanaa1988@gmail.com, ${ }^{4}$ sk_dutta@yahoo.com
ISSN

Print 0974-7893

Abstract: Observations on the Indian Spiny-tailed Lizard Saara hardwickii (Gray, 1827) were undertaken in Tal Chhapar Wildlife Sanctuary, Rajasthan, India during the monsoons (July) following quadrat sampling that was time-constrained. The study revealed that the area is one of the preferable habitats for the species. A population analysis showed that the relative abundance of the subadults was higher, followed by juveniles and adults during the study period. The beginning of activity of the lizards was found to vary over the study period depending on prevailing weather conditions. The activity pattern was bimodal, except across rain events. The study revealed two important ecological findings about these lizards; complete sealing of burrow during rains which differed from partial sealing on normal days and complete diurnal cycle of body colour changes during the monsoon. Feeding was the predominant activity of this lizard followed by basking, resting and chasing each other. The adult lizards were found to be strictly herbivorous, in spite of an abundance of insects available in the area during the period. Subadults and juveniles were found to eat both plant parts, as well as insects. Microhabitat use such as inside grass clumps was found to be higher followed by barren ground, under shade and on stones.

Keywords: Activity pattern, borrow sealing, colour change, food and feeding, habitat use, population, Rajasthan, Spiny-tailed Lizard, Wildlife Sanctuary.

Hindi Abstract: ताल छापर वन्यजीव अभ्यारण्य में भारतीय कॉटेदार-पूछवाली छिपकली Saara hardwickii (Gray, 1827) पर वैज्ञानिक अनवेक्षण किया गया। अध्ययन क्वाडरेट विधि (quadrat sampling method) और सिमित समयावधि (time-constrained) से मानसून अवधि के जुलाई माह में किया गया। अध्ययन में यहॉ का वास-स्थान इस प्रजाति के लिए मुख्य रुप से पसंदिदा वास-स्थान पाया गया। जनसंख्या विश्लेषण में अर्धवयस्क की संख्या सबसे ज्यादा, किशोर और वयस्क की उत्तरोतर संख्या कम पाई गई। इस प्रजाति के दैनिक गतिविधियों के समय में महत्त्वपूर्ण रुप से मौसम के अनुरुप दैनिक परिवर्तन पाया गया। इसका दैनिक क्रियाक्लाप, वर्षा के समय को छोडकर, बाईमोडल देखा गया। इस अध्ययन में मुख्य रुप से इस प्रजाति के दो पारिस्थितिकी पहलू निकल कर आए; वर्षा के दौरान बिल को पूर्णतया बंद करना वहीं सामान्य दिनों में आधा बंद करना और इसके दिन के समय शरीर के रंग को परिवर्तित करने का चक्र। दैनिक क्रियाक्लाप में खाना खाने में सर्वाधिक समय व्यतीत किया गया वही सूर्य की रोशनी में शरीर को तापना, आराम करना और एक-दूसरे का पिछा करना इसकी अन्य गतिविधियॉ थी। वयस्क छिपकलियॉ पूर्णतया शाकाहारी देखी गई, वही मानसून अवधि में किटों की बाहूल्यता थी। अर्धवयस्क और किशोरों को पादपों के भाग के साथ- साथ किटों का भी भक्षण करते देखा गया। इस प्रजाति द्वारा सुक्ष्म वास-स्थान के रुप में घास के झुण्ण सबसे पसंदिदा देखा गये वही सपाट धरतल, छाया और छोटे पत्त्थर क्रमशः कम पसंद किये गये।

DOI: http://dx.doi.org/10.11609/JoTT.02806.484 | ZooBank: urn:Isid:zoobank.org:pub:77C4591F-6D2E-4F3A-ABE5-5C6AE7128EA5

Editor: C. Srinivasulu, Osmania University, Hyderabad, India.

Date of publication: 26 January 2013 (online \& print)

Manuscript details: Ms \# 02806 | Received 15 May 2011 | Final received 31 October 2012 | Finally accepted 02 January 2013

Citation: Das, S.K., S. Dookia, K. Das \& S.K. Dutta (2012). Ecological observations on the Indian Spiny-tailed Lizard Saara hardwickii (Gray, 1827) (Reptilia: Squamata: Agamidae) in Tal Chhapar Wildlife Sanctuary, Rajasthan, India. Journal of Threatened Taxa 5(1): 3516-3526; doi:10.11609/JoTT.o2806.484

Copyright: (C) Das et al. 2013. Creative Commons Attribution 3.0 Unported License. JoTT allows unrestricted use of this article in any medium reproduction and distribution by providing adequate credit to the authors and the source of publication.

Funding: None.

Competing Interest: None

Acknowledgements: The authors are grateful to the Department of Forest, Government of Rajasthan, for granting permission to carry out this work in the Tal Chhapar Wildlife Sanctuary, Churu, Rajasthan. Our hearty thanks goes to Mr. Surat Singh Puniya, the Range Officer, Dept. of Forest, Churu and Mr. Harlal Singh, Assistant Conservator of Forests, Government of Rajasthan for their timely co-operation during the study. We are also grateful to the forest guards and other forest officials for all their valuable assistance during the work. Special thanks are due to Dr. Pankaj Joshi, Scientist, Gujarat Institute of Desert Ecology, Bhuj, Gujarat for his help for identification of plants. Thanks are also due to Dr. Justus Joshua, Senior Scientist, FES, Rajasthan, and Dr. Wesley Sunderraj, Senior Scientist, Gujarat Institute of Desert Ecology, Bhuj, Gujarat, for their valuable suggestions during this work.

Author Contribution: All authors have significant contributions in the present work. The first three authors have contributed starting from the field studies to preparation of the manuscript. The last author provided valuable suggestions and critical comments on findings of this work at every step, and in the final editing of the manuscript. 


\section{INTRODUCTION}

The eastern spiny-tailed lizards of the genus Saara are represented by three species worldwide (Wilms et al. 2009a). In India, only one species, S. hardwickii (Gray, 1827) is found, which has a patchy distribution in India, Pakistan and Afghanistan (Khan \& Mahmood 2004; Knapp 2004; Wilms et al. 2009a). It is the only herbivorous lizard species in India, which is currently distributed largely in small fragmented populations in the dry areas of northwestern India in the Thar Desert of Rajasthan and Gujarat (Das 2002; Daniel 2002; Sharma 2002; Wilms et al. 2009a). The main threat to this lizard is commercial exploitation for its meat, skin and oil, the latter supposedly having great medicinal value. This species is threatened due to illegal trading and habitat destruction. However, due to a lack of proper information on this species it has been considered as Data Deficient nationally (Molur \& Walker 1998). This paper provides data on the ecology of this species based on a study undertaken in the Tal Chhapar Wildlife Sanctuary, Sujangarh Tehsil, Churu District, northeastern Rajasthan, India.

\section{Study Area}

The Tal Chhapar $\left(27^{\circ} 48^{\prime} 38^{\prime \prime} \mathrm{N} \& 7^{0} 26^{\prime} 88^{\prime \prime} \mathrm{E}\right.$; area 780ha; Fig. 1), initially managed as a private hunting reserve of the Maharaja of Bikaner, was declared as a Wildlife Sanctuary in the year 1962. This Sanctuary is famous as a 'Blackbuck Sanctuary' and supports a good population of the Indian Spiny-tailed Lizard (4039 lizards; Anonymous 2010). The study area comes under the biogeographic zone 3A-Thar Desert (Rodgers et al. 2002). The vegetation of this area has been classified as northern tropical thorn forest (6B) and subclassified as desert thorn forest (6B/C1) (Champion \& Seth 1968).

A major part of Tal Chhapar (in Rajasthani Tal means plain) is a flat saline terrain which changes into a wetland during the monsoons due to a collection of rain water from nearby areas. It is one of the best grassland habitats in India. The maximum temperature reaches up to $49^{\circ} \mathrm{C}$ in June and the minimum temperature dips to $1-2{ }^{\circ} \mathrm{C}$ during December-January. Rainfall in this region is highly erratic with a large variation in mean annual rainfall. The area witnessed droughts in 2003 and 2005, heavy rain in 2008 and cyclone in May 2009 in the last decade.

\section{METHODS}

The field study was undertaken during the monsoon from 1-31 July 2010. Data collection was carried out following quadrat sampling method that was timeconstrained (Campbell \& Christman 1982; Vogt \& Hine 1982). During the study, each day was divided into 12 one-hour time classes (from 0600-1800 hr) and sampling was done in two such time classes per day, one in the morning shift and one in the afternoon shift.

Plots of $15 \times 15 \mathrm{~m}^{2}$ were laid and one such plot was taken for observation in a time class in the morning and afternoon shift each, so that two plots per day and a
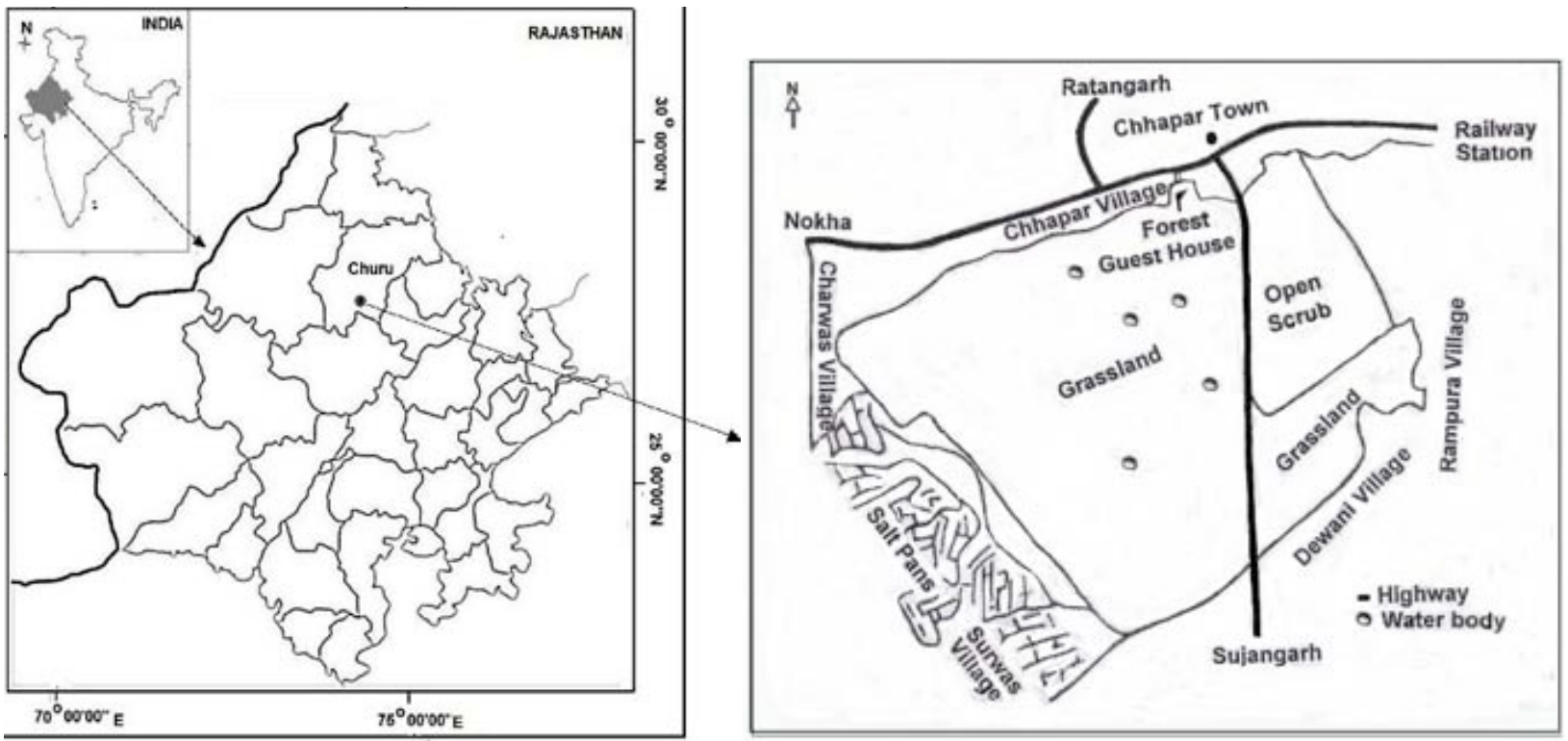

Figure 1. Map of Tal Chhapar Wildlife Sanctuary 
total of 62 plots were studied during the entire study period. For each plot, observations were repeated after every 18-minute time interval with a time gap of two minutes. This repetition of observations within a time class was done to get the maximum data on activity and microhabitat preferences since this study was a short term study. On rainy days when no lizards were sighted outside their burrows, no such plots were studied, which was adjusted on the next few days by taking more plots for study. Observations at a distance of $3 \mathrm{~m}$ from the boundary of the quadrats was carried out with the help of $8 \times 40$ binoculars so as to note ecological aspects such as age, activity and microhabitat of the lizards without disturbing them.

\section{Population Analysis}

For the population analysis, the number of lizards sighted in each quadrat for each time interval (18 minutes) was noted, so that the number of lizards for three time intervals were noted for a time class. Since observations were repeated three times within a time class, during the analysis of the data, only, one-third of the lizards sighted during the whole time class was taken into consideration to avoid repetition and overestimation of the population.

The number of active burrows was also enumerated in the same quadrat on the same day by observing their trails or fresh pellets in nearby areas when lizards were day resting (Wilms et al. 2009b) in order to avoid any type of disturbances to them.

According to Wilms et al. (2009b), the age group of spiny-tailed lizards can be identified based on their total length. During this study for every sighting, specific age group that is, adult (total length $\geq 35 \mathrm{~cm}$ ), subadult (total length $<35 \mathrm{~cm}$ ) or juvenile (total length $\leq 20 \mathrm{~cm}$ ) was noted based on visual estimation. Juveniles were identified based on their size as well as dark blotches on their skin, while subadults and adults were distinguished based on size difference only (Images 1-4). Density or abundance of lizards during the study period and relative abundance of each age group was calculated using the following formulae (Ludwig \& Reynolds 1988;
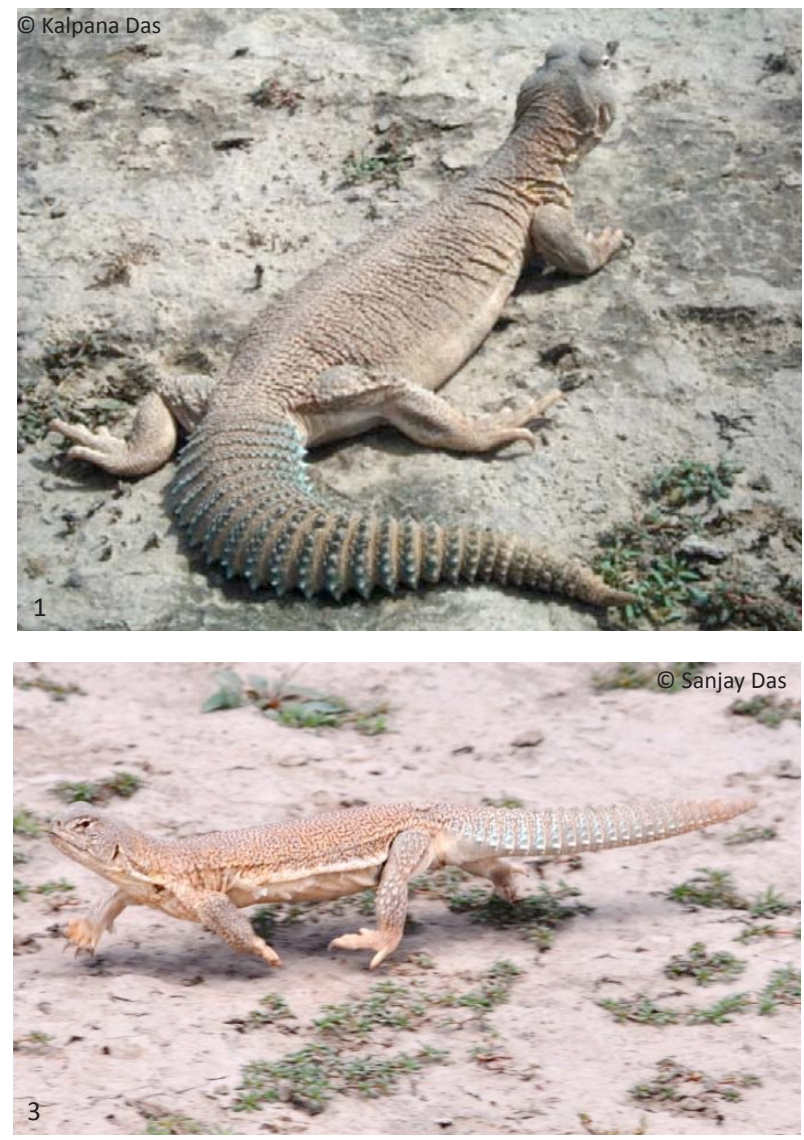
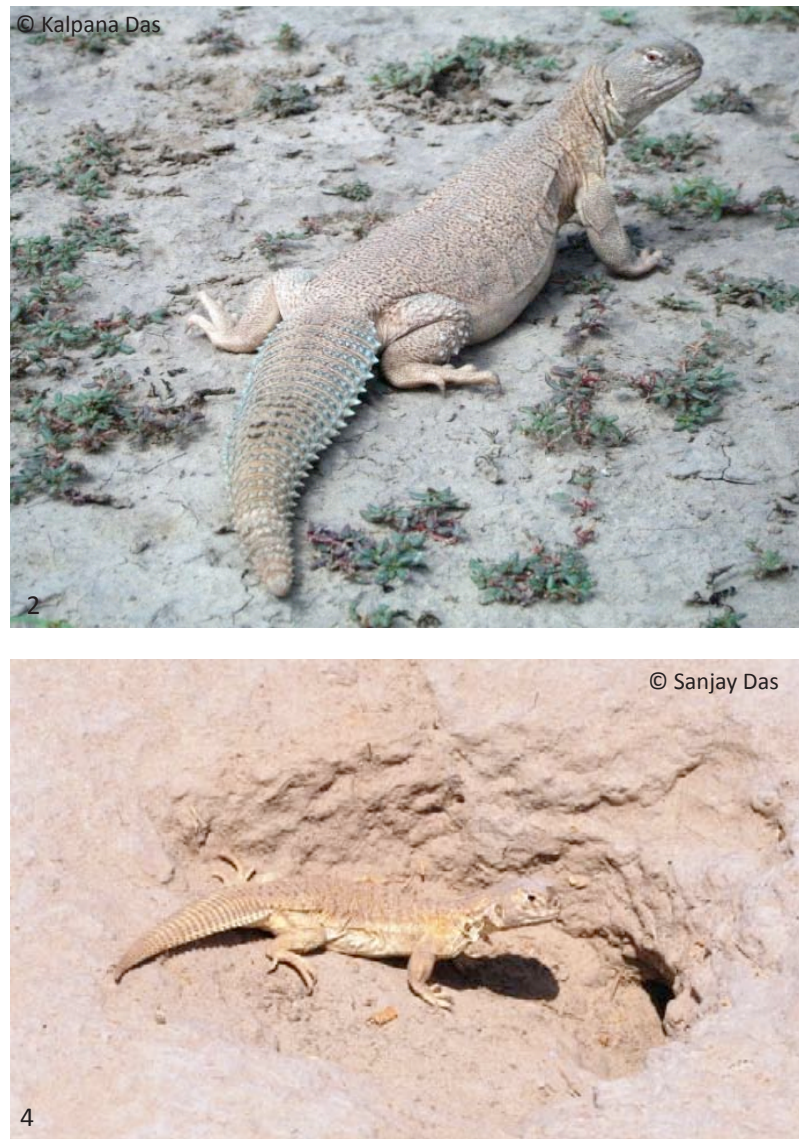

Images 1-4. Indian Spiny-tailed Lizard Saraa hardwickii:

1 - Male; 2 - Female; 3 - Alarmed subadult running with tail above ground; 4 - Juvenile near burrow. 
Henderson 2003).

Density $=\mathrm{N} / \mathrm{A}$

where, $\mathrm{N}=$ total number of individuals;

$$
A=\text { total area }
$$

relative abundance $=\left(n_{i} / n\right) \times 100$

where, $n_{i}=$ total number of individuals of particular age group sighted;

$\mathrm{n}=$ total number of individuals of all age groups sighted

\section{Activity}

All lizards sighted outside the burrows and other retreats were termed active (Pandav \& Choudhary 1996). Activities were classified into four categories-basking (lying in the sun in the open area without moving any part of the body and noticed in the same condition for more than five minutes when undisturbed), resting (lying in the shade to avoid direct sun), foraging (actively searching for food or feeding), and chasing (fighting or encountering each other while foraging). The activity during which a lizard was sighted for its first encounter within a time interval was noted. As they change their place for a particular microhabitat meant for specific activity (Pianka 1986), when undisturbed and noticed running the activity after stopping was noted.

\section{Food and Feeding}

Twenty $1 \times 1 \mathrm{~m}^{2}$ plots were laid at different locations (in accordance with burrow density) for vegetation sampling. Density of plants was determined using the above mentioned formulae.

Fresh pellets were collected near the burrows of each age group of lizards whenever available (by selecting five burrows for each age group at different locations) and also from foraging sites. Pellets were examined in the field and also collected for later analysis. Plant materials present in the pellets were examined under the microscope in the laboratory. Fifty pellets of each age group were examined during the study.

\section{Microhabitat Use}

The habitat of this lizard was almost homogenous during the study period because the entire habitat was a flat plain with only two types of variations namely, barren ground with patches of grass cover or grassland with patches of open areas. Both the types were almost equally available during the first half of the study period, though due to rain, a major portion of the habitat changed into grassland with patches of open areas during the second half of the study period. Stones, xerophytic bushes and trees were present at places in both the types. Hence, only four types of microhabitats of this lizard were noticed during the study, namely, inside grass clumps (IG), on barren ground (BG), under shade (US) and on stones (OS). The microhabitat in which a lizard was sighted for its first encounter within a time interval was noted. When found running the microhabitat chosen by the lizard after stopping was noted.

\section{RESULTS}

The density of lizards recorded in the present study was $413 /$ ha and that of active burrows was $324 /$ ha. No population was observed outside the protected area except one population on the outskirts on its northern side, which was not included in the present study. The number of subadults (48\%) was higher in the population followed by juveniles (31\%) and adults (21\%) (Fig. 2).

This species is diurnal, lives in colonies, and is a solitary burrow-dweller. At one instance three newly hatched juveniles (whose total length was between 12-15 cm) were found emerging from one burrow along with their mother, and followed their mother during foraging (Image 5) though other juveniles in the area were foraging singly. After foraging was over, they followed their mother until they reached their burrow where the mother put them back into the burrow by grasping them with her teeth, indicating parental care in this lizard.

In the present study, the beginning of activity of the lizards showed a wide variation (Fig. 3) and was in accordance with the prevailing weather conditions. During normal hot days the lizards were found to be

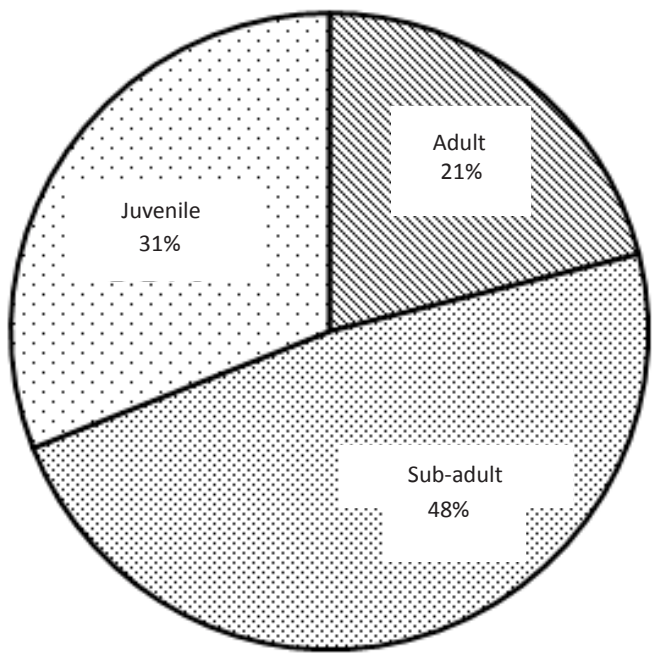

Figure 2. Percentage Age Structure $(n=1728)$ 


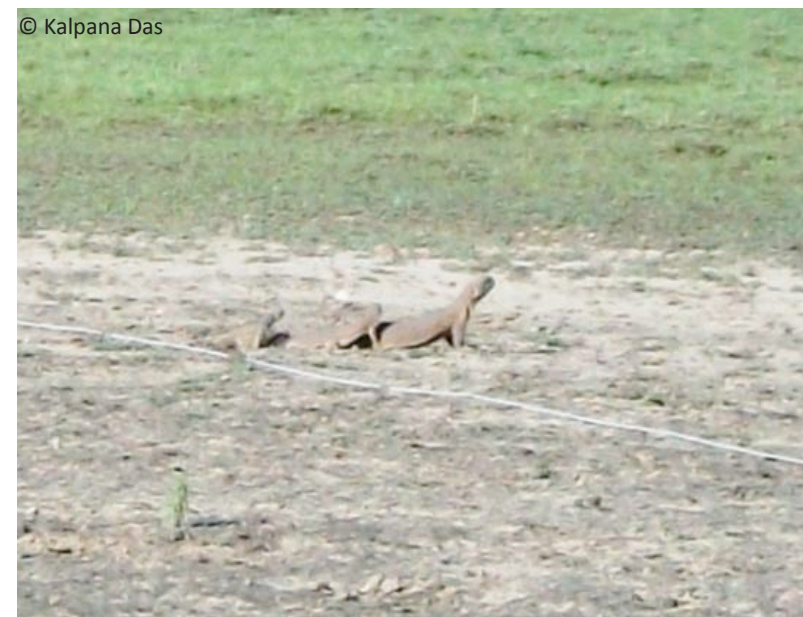

Image 5. Two juveniles while feeding with mother

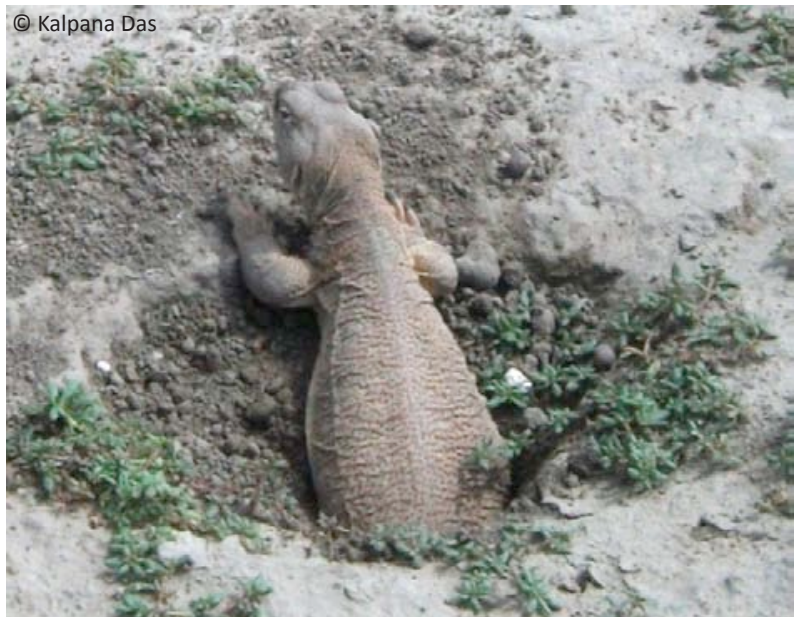

Image 6. Lizard scanning the surrounding before emerging active in the early hours of the morning and at the earliest, active at $0615 \mathrm{hr}$. The beginning of activity was found to be late on cloudy days, with the earliest start of activity observed at $0820 \mathrm{hr}$. Before coming out of their burrows the lizards emerge head first and scan the surroundings for any threat (Image 6). Their initial activity was observed to be basking followed by feeding on the surrounding vegetation, taking short rests in between. The lizards were found to spend a maximum time feeding (51\%), followed by basking (27\%), resting $(14 \%)$ and chasing each other (8\%).

The lizards were found to be strictly territorial with a homing instinct. It was found that generally the lizards go up to $15 \mathrm{~m}$ from their burrow for feeding. They remain alert while feeding, run very fast, and back to their respective burrows on the slightest hint of disturbance, mainly from predators. When many lizards feed together, they maintain a minimum safe distance of half to one meter between them. If they are nearer than this they chase each other (Image 7). While fighting and in an alarmed state, their tail tip was found to be curved upwards (Image 8). When running in an alarmed state, the tail is above ground (Image 3 ). The tail is along the ground when the lizard runs during its normal activities.

The activity was found to be bimodal throughout the study on normal days while unimodal or not at all during the rains as they remain inside their sealed burrow. The peak activity was found to be between 0800-1000 hr during hot days, shifting to $1000-1200 \mathrm{hr}$ on cloudy days. On normal hot days they continue their morning activity till noon, though only a few lizards remain active after noon. They again start their afternoon activity at about $1700 \mathrm{hr}$ which continues till $1900 \mathrm{hr}$.

The lizards live in burrows with a semicircular opening. After completing their morning feed they rest in their burrows, generally without sealing them, but

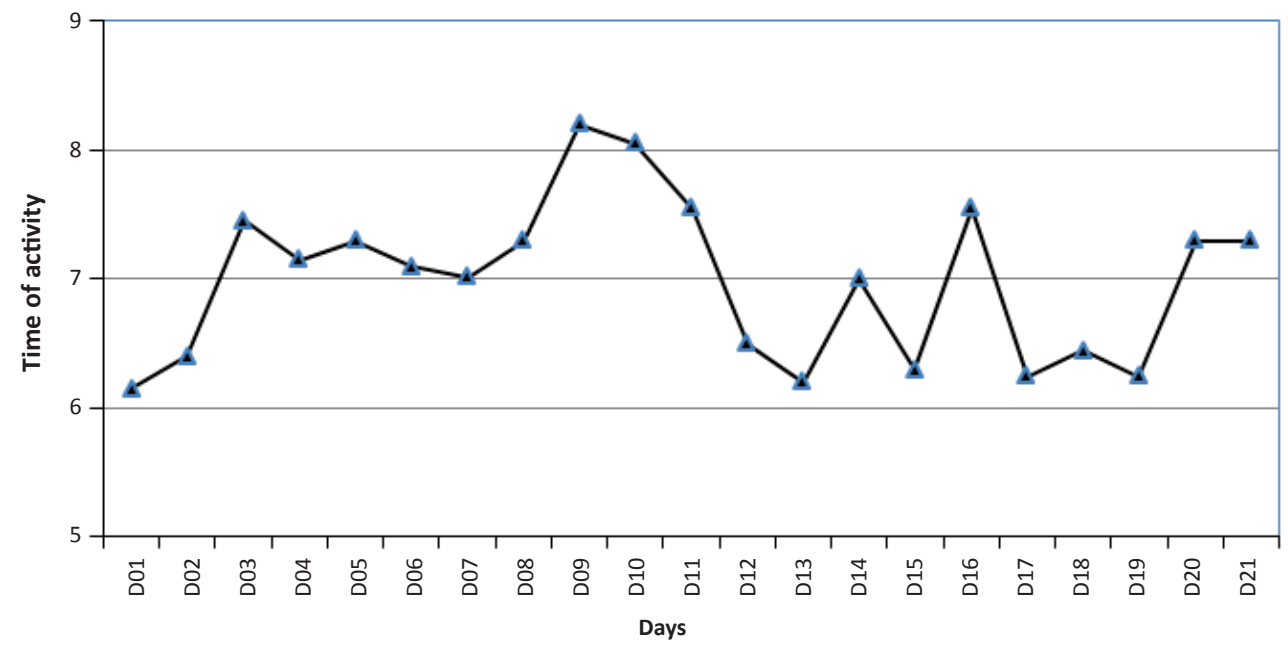

Figure 3. Emergence time of lizards from burrows 


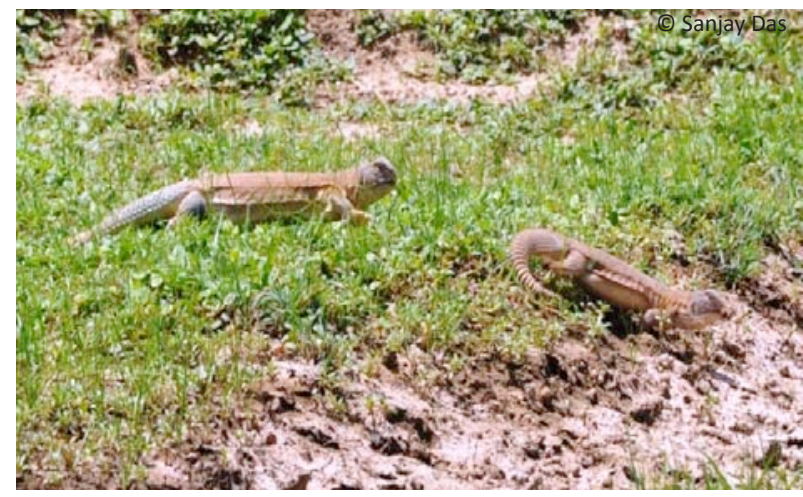

Image 7. Two adult lizards chasing each other while feeding

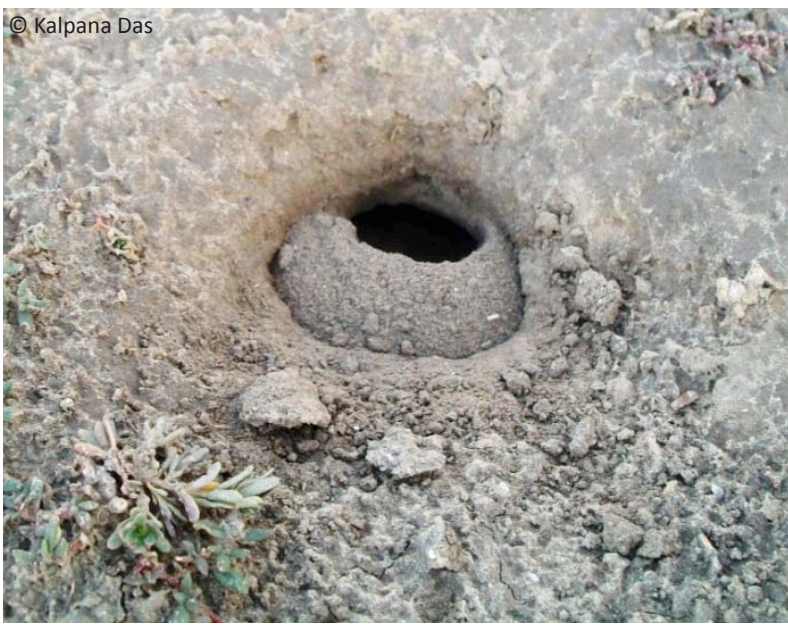

Image 9. Partially closed burrow in normal days

after their evening activity they go into their burrow and seal them with loose soil leaving a small crescent-shaped opening (Image 9). It is interesting to note here that with the onset of rain they completely seal their burrows with tight soil and remain inside their burrow during rain (Image 10). The complete sealing of the burrow is to avoid entry of rain water into their burrow, which is supported by one observation after rain in which one lizard was found dead in its open burrow filled with rain water (Image 11). The lizards close their burrow within five minutes of the onset of rain, or in a few instances just with a cloudy overcast. From inside the burrow they close the opening by a vigorous movement of their tail throwing soil towards the burrow mouth. After the end of the rain spell, they clean their burrow with the help of their tail again replacing the wet soil by dry soil from inside.

Moulting behaviour was also observed in many lizards as additional dead skin folds were observed on their body during the study (Image 12), both in males

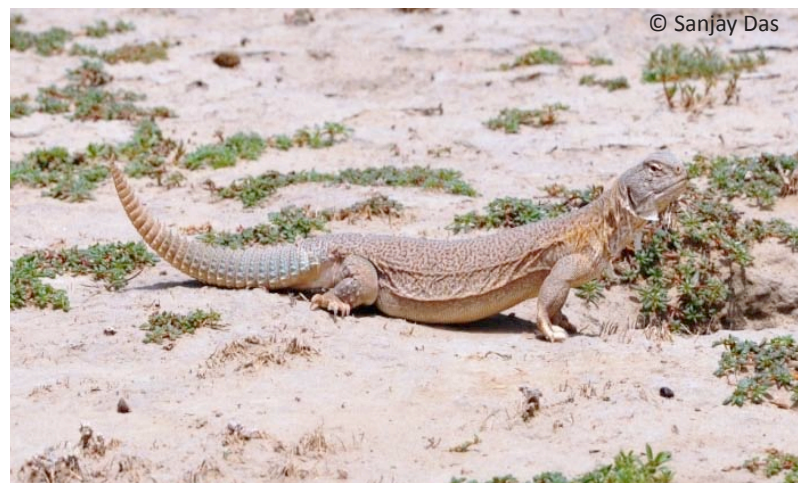

Image 8. Lizard when alert (tail directed upward)

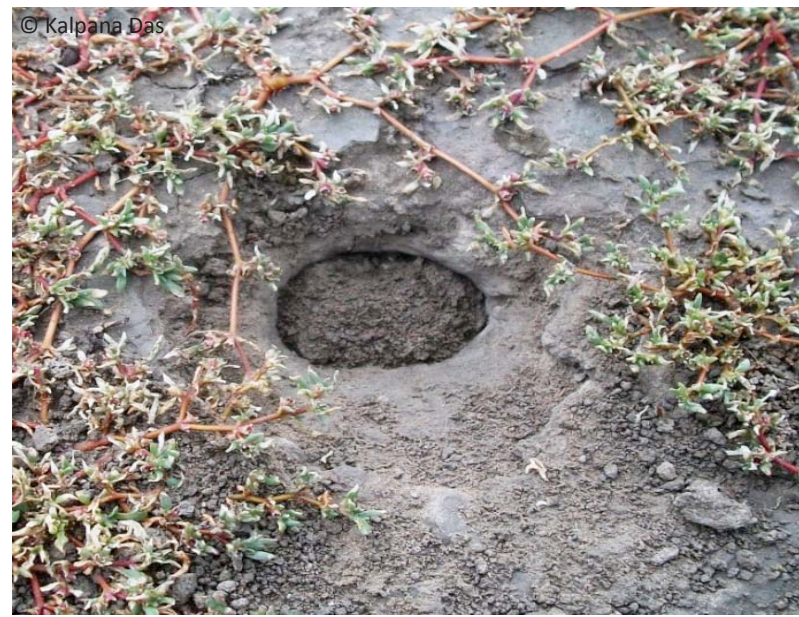

Image 10. Completely closed burrow during rain

and females. A shed skin was observed lying near one burrow opening and one female was seen shedding part of her dead skin by rubbing her body against the ground. Ingestion of the shed skin was also observed.

Diurnal changes in body colouration were observed in these lizards. In the morning shift, when the lizards come out of their burrow the body colour is light brown, but it changes to dark brown after sometime (1/2-1 hr), which remains for a considerable period (1-2 hr) of time after which the colour starts fading. Similarly, with the beginning of activity, the tail is light brown, but soon it develops a tinge of blue colour along the spines and thigh (Image 13) by the time body colour changes to dark brown. The blue tinge also darkens and remains for a considerable period (1-2 hr) of time after which it starts fading. Sometimes both dark body as well as blue tinge along the spines and thigh is retained in the entire morning shift. No such colour changes were noticed during the afternoon shift.

From field observations it was found that adult lizards 


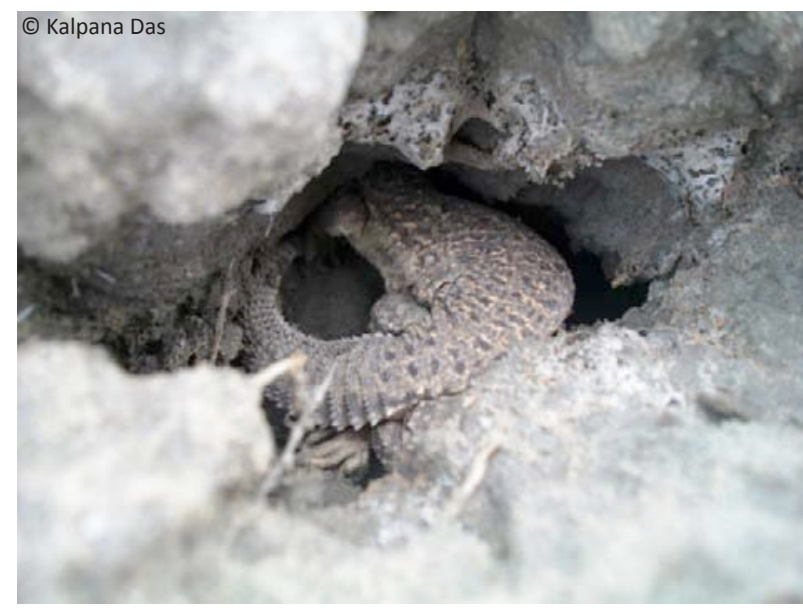

Image 11. Dead Spiny-tailed Lizard in flooded burrow

feed strictly on plant parts in spite of an abundance of insects available in the area during the monsoon season. Subadults and juveniles were found to feed on both plant parts and insects, though juveniles spent a maximum amount of time feeding only on insects such as beetles, soil mites including velvet mites, spiders, grasshoppers, moths and caterpillars. From pellet analyses, it was observed that, insect parts were present only in $4 \%$ pellets of adults, their quantity being negligible (1-2\%) as compared to plant material (the rest). In pellets of subadults and juveniles, plant parts as well as insects were observed. A few (8\%) of their pellets had insect remains alone, while in other pellets a considerable amount (about 30-70 \%) of plant materials were observed. Major insect remains in their pellets were of beetles. Microscopic analysis of the plant materials in the pellets revealed that they feed mostly on leaves and stems and cannot digest the cuticle.

During the study the lizards were found to feed on six plant species, and remains of Portulaca quadrifida

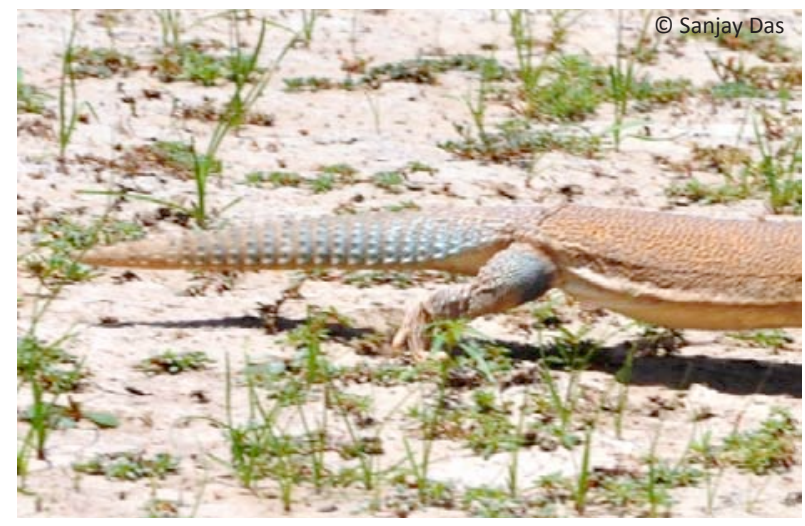

Image 13. Blue tinge along the tail and thigh region

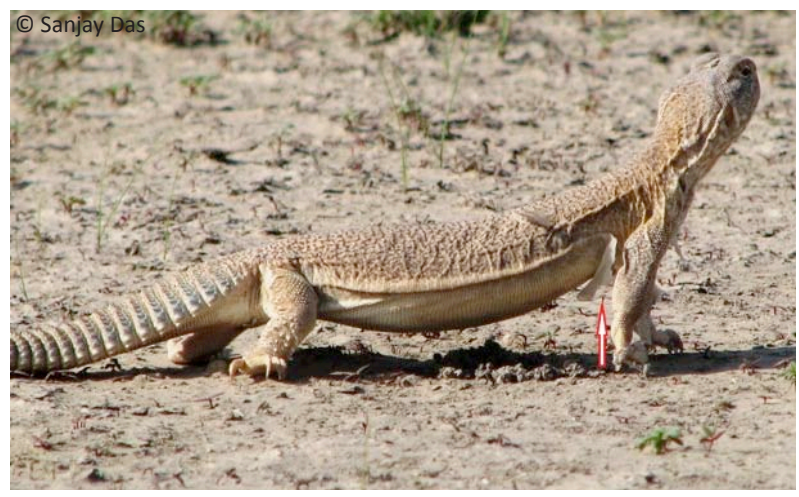

Image 12. Moulting (skin fold marked by arrow)

(Image 14) and Boerhavia diffusa (Image 15) were present more in their pellets in comparison to other plants. In their habitat, there was an overall relative abundance of Portulaca quadrifida followed by Cyperus rotundus, unidentified species A, Boerhavia diffusa, Portulaca oleracea, unidentified species B and Suaeda fruticosa (Fig. 4).

Most of the time the lizards were seen inside grass clumps (51\%), followed by barren ground (35\%), under shade $(9 \%)$ and on stones $(5 \%)(n=1728)$.

The Indian Spiny-tailed Lizards' predators are crows and raptors. In one instance, a Sand Boa Eryx johnii was observed entering the burrow after chasing the lizard (Image 16) and probably fed on the lizard. During the study period, on two occasions, the remains lizards were found near the dens of Common Fox Vulpes bengalensis (Image 17).

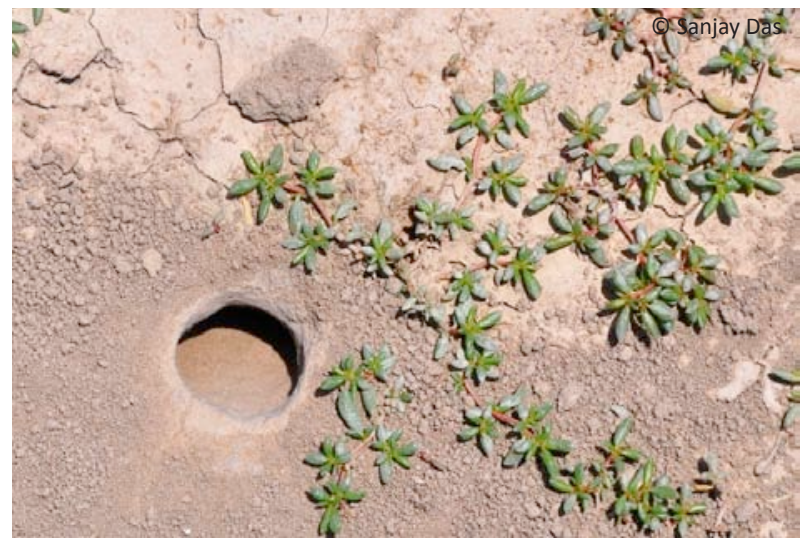

Image 14. Portulaca quadrifida 


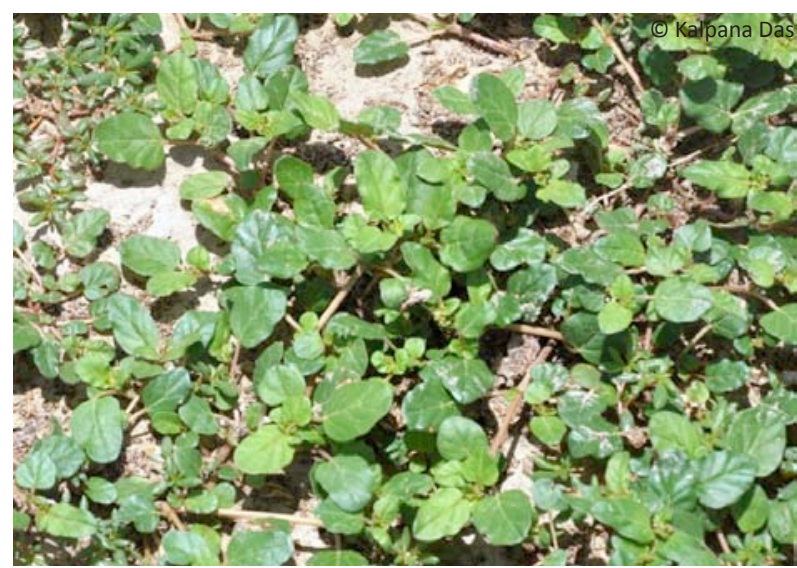

Image 15. Boerhavia diffusa

\section{DISCUSSIONS}

The density of active burrows (324/ha) and lizards $(413 /$ ha) was far greater than that reported from Kachchh Desert of Gujarat (42.45 burrows/ha in summer and 66.04/ha during the monsoon and 34 lizards/ha in summer and 28/ha during the monsoon; Dutta \& Jhala 2007). But burrow density was moderately high in comparison to the density of active burrows of this lizard in other areas of Thar Desert of Rajasthan, which ranged from 14-1000 (Ramesh 2008). This clearly shows that the area is an important habitat for this species. A higher density of lizards in comparison to active burrows also revealed that some juveniles were still sharing burrows with their mother during the study period.

In the population, the relative abundance of subadults was high, followed by juveniles and adults during the study period. According to Dutta \& Jhala (2007) in Kachchh Desert of Gujarat the relative abundance of hatchlings was higher followed by juveniles, subadults and adults during the monsoon. They have classified the population of Indian Spiny-tailed Lizards into four

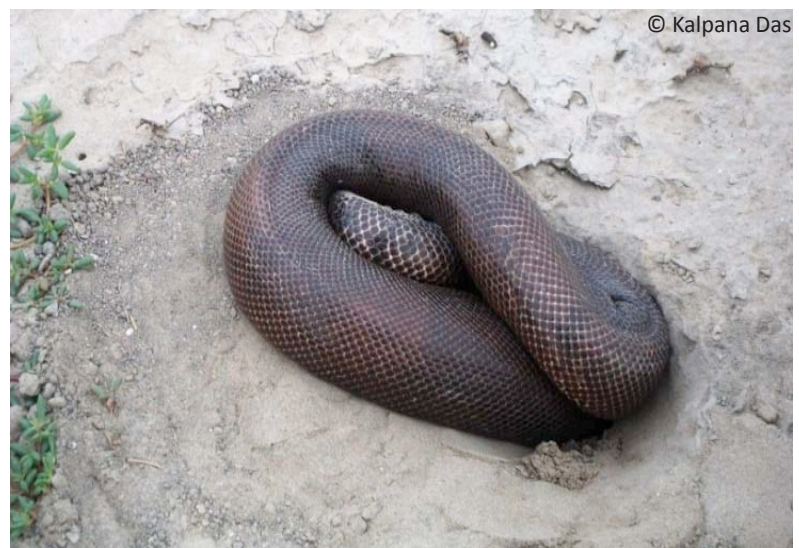

Image 16. Sand Boa entering a lizard burrow

age groups, namely, adults, subadults, juveniles and hatchlings based on burrow diameter only and not considered direct count age group-wise.

This study shows that the initial time of activity of this lizard varied over a wide time range and is in accordance with the prevailing weather conditions. This supports the view of Cloudsley-Thompson (1992), and Wilms et al. (2009b) that spiny-tailed lizards are highly seasonal with respect to activity/visibility outside of their burrows. The study revealed that the activity pattern is bimodal during the monsoons except when it rains. It becomes unimodal or shows no activity depending upon rain since it remains inside its closed burrow during the rain. This is in contrast to the findings of Dutta \& Jhala (2007) wherein shifting of activity from bimodality in summer to unimodality during the monsoon was reported.

The study also brought to light an important ecological finding hitherto not reported: that of complete sealing of burrows during rains compared to partial sealing during normal days. The closing of burrows during the rain was to avoid the flooding of burrows which was reported in desert ants (Cloudsley-Thompson 1992). The sealing

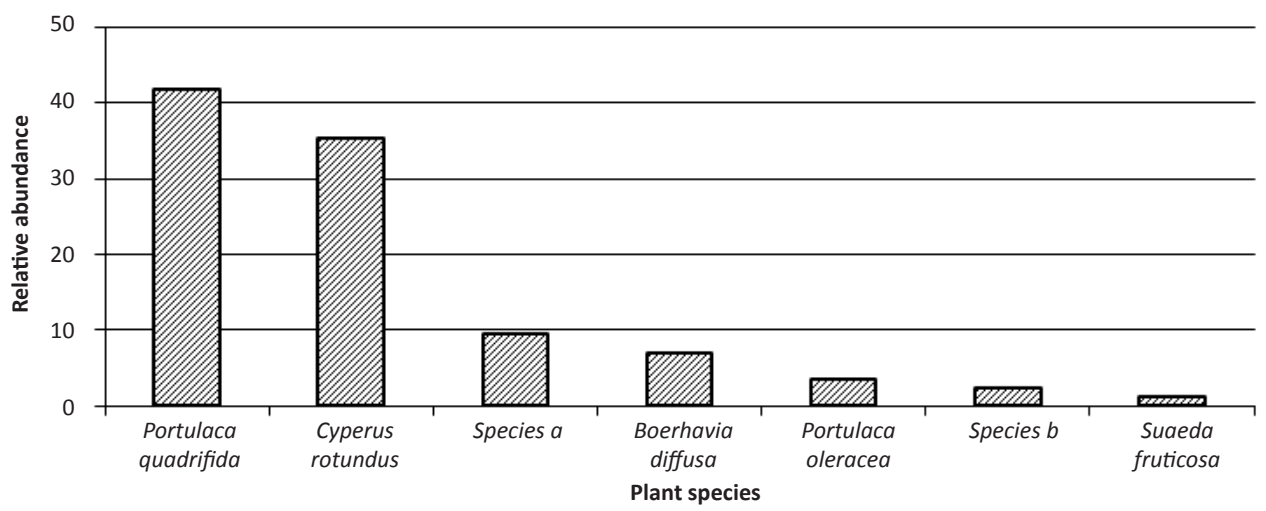

Figure 4. Relative abundance of plants (number of quadrats (20) 


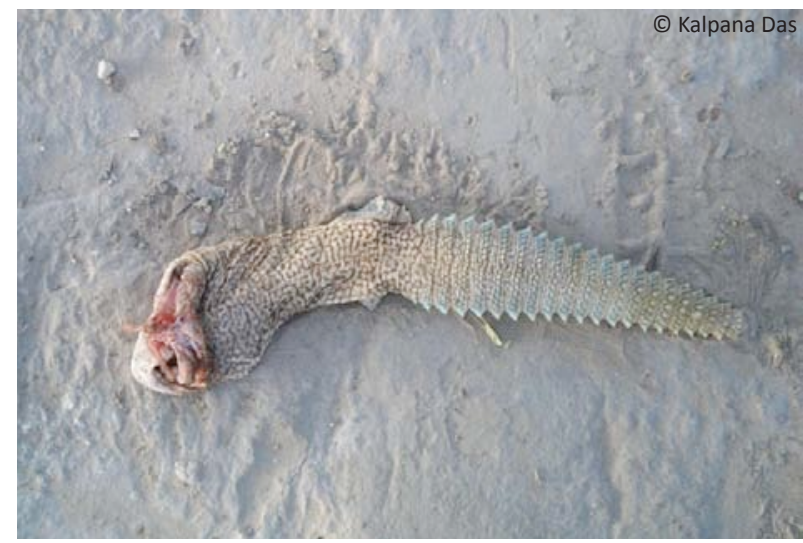

Image 17. Tail-part of Spiny-tailed Lizard near den of fox

of burrows maintains a thermal refuge for these lizards under temperature extremes as reported by CloudsleyThompson (1992), Cunningham (2001), Dutta \& Jhala (2007), and Wilms et al. (2009b); in contrast to the wide range of daily and annual fluctuations of air and soil temperatures, the temperatures within their burrow remains remarkably constant and protects them from water loss as well as predators. However, partial closing of burrows in normal days showed that they spend less energy in sealing and cleaning activity which is one of the adaptations in harsh desert conditions. It supports the views of Cunningham (2001) from his studies on Egyptian Spiny-tailed Lizards that den cleaning is a time consuming and an energetically costly affair.

During the study the lizard spent most of its time outside its burrow feeding which showed the lizard comes outside mostly for foraging (Video 1). Juveniles feed while their mother keep vigil and share a common burrow with her, an observation also made by Minton (1966), Bhanotar \& Bhatnagar (1977), and Dutta \& Jhala (2007). During fighting and in the alarmed state, the tail of the lizard was found to be curved, with tip directed upward, as has been reported by Das \& Pandey (2005). This is also reported in other lizards and correlated to signal an awareness of threat (Caro 2005).

Moulting was also commonly observed among these lizards during the study which is correlated with an abundance of food during the monsoon, and the lizard spends a considerable amount of energy in this activity. The lizard eating its own shed skin observed during the study was earlier reported in other lizards (Bustard \& Maderson 1965), which is to fulfil the nutrient requirements.

Studies by Cloudsley-Thompson (1992), SchmidtNielson (2002), and Dutta \& Jhala (2007) with regards to body colour changes in lizards reported that darker pigmentation appears at lower temperatures and lighter pigmentation at higher temperatures. During the study similar changes in body colouration has been observed. Although, our finding contrasts that of Dutta \& Jhala (2007) about monsoon body colouration; they observed that the lizard retained a dark brown colouration throughout the day during the monsoons.

In this study, both from field observations and pellet analysis, adults of this lizard were found to be strictly herbivorous during monsoon as has been earlier reported by Anderson (1898), Purves (1915), Smith (1935), Krishna (1955), Krishna \& Dave (1956), Schmidt \& Inger (1957), Cloudsley-Thompson \& Chadwick (1964), Minton (1966), Kevork \& Al-Uthman (1972), Sharma \& Vazirani (1977), Cunningham (2001), Sharma (2002), Das \& Pandey (2005), and Wilms et al. (2009b). The presence of a negligible amount of insect parts in their diet appears to have been ingested accidentally along with the plant parts. Subadults and juveniles were found eating both plant parts, as well as insects. Studies by Pope (1955), Minton (1966), and Mayhew (1968) show that the teeth of young ones of this lizard differ from that of adults and that accounts for the insect diet of the young ones.

Pradhan (1971), Bhanotar et al. (1972, 1973), Bhanotar \& Bhatnagar (1972), Pradhan et al. (1973), and Dutta \& Jhala (2007) reported that the adults of this lizard can also eat insects and are hence not strictly herbivorous. Except Dutta \& Jhala (2007), observations of all others opposing the strict herbivorous nature of adults of this lizard were based on the feeding of insects to this lizard in captivity.

The finding of Dutta \& Jhala (2007) is based on an analysis of the seasonal food habit of the lizard from pellet analysis as well as a recording of a percentage of bites for each available food item following focal animal sampling. They had not clearly mentioned about morphological differences among the various age groups and also not classified pellets and bites according to different age groups, though they followed the scan sampling method for recording the activity of the lizard age group-wise. Hence, their objection to the ontogenic dietary shift of this lizard from insectivory in juveniles to herbivory in adults as reported by Pope (1955), Minton (1966), and Mayhew (1968) is confusing. But from the observation of feeding of these lizards on insects in captivity, as earlier reported, it can be concluded that though the adults of this lizard are strictly herbivorous, they also feed on insects during unavailability or scarcity of food. It is a kind of adaptation in an arid ecosystem, because the desert being a harsh ecosystem, animals living in this 
ecosystem show tolerance towards a wide range of food items (Pianka 1986; Cloudsley-Thompson 1992; King 1996). However, this needs further investigation.

More amount of remains of Portulaca quadrifida in the pellets of this lizard in comparison to other plants can be correlated with a higher availability of this plant during the study period.

During the study the microhabitat use inside grass clumps was found to be high in comparison to other types of microhabitats. Since the lizard spends a maximum amount of time outside its burrow feeding, and overall availability of grassland was more in comparison to other types of microhabitats during the study, microhabitat preference for vegetation seems to be high. However, the lizard was also observed selecting the other three types of microhabitats similar to observations made by Pianka (1986), and Cloudsley-Thompson (1992) that the microhabitat selection by ectothermic animals like lizards is an important desert adaptation, by which the animal compensates for extreme temperature changes by exploiting spatial heterogenieity in thermal conditions.

The present study revealed that the Indian Spinytailed Lizards were preyed on by foxes, raptors, crows and snakes. Observation on the predation of spinytailed lizard by a sand boa which was earlier reported by Pardeshi et al. (2008) indicates that this snake is possibly a common predator of the lizard.

\section{REFERENCES}

Anderson, J. (1898). Zoology of Egypt: Reptilia and Batrachia, Vol-I. Bernard Quatitch, London, 372pp.

Anonymous (2010). Report: Vanya Jeev Ganana, Maah April' 2010 Abhyarana Chhapar Range, Sujanagarh, Mukhyalaya-Chhapar. Department of Forest, Rajasthan, India, 10pp.

Bhanotar, R.K. \& R.K. Bhatnagar (1972). Desert locust upsurve vis-avis predatory fauna. Entomologists News Letter 2(8): 53.

Bhanotar, R.K. \& R.K. Bhatnagar (1977). Behaviour, colouration, lepidosis and pre-ano-femoral pores in juveniles of Uromastyx hardwickii Gray. Journal of the Bombay Natural History Society 74(2): 364-365.

Bhanotar, R.K., R.K. Bhatnagar \& Y.N. Srivastav (1972). Further observations on the dietary habits of spiny-tailed lizard Uromastix hardwickii Gray. Entomologists News Letter 2(5): 34.

Bhanotar, R.K., R.K. Bhatnagar, Y.N. Srivastav \& Y. Mahto (1973). Preliminary studies on locust hopper predation by Uromastix hardwickii Gray. Entomologists News Letter 3(3): 19-20.

Bustard, H.R. \& P.F. Maderson (1965). The eating of shed epidermal material in squamate reptiles. Herpetologica 21(4): 306-308.

Campbell, H.W. \& S.P. Christman (1982). Field techniques for herpetofaunal community analysis, pp. 193-200. In: Norman J. Scott Jr. (eds.). Herpetological Communities. Wildlife Research Report No-13, U.S. Department of the Interior, Fish \& Wildlife Service, Washington D.C., iv+239pp.

Caro, T. (2005). Antipredator Defences in Birds and Mammals. The University of Chicago Press, 591pp.

Champion, H.G. \& S.K. Seth (1968). A Revised Survey of the Forest
Types of India. Government of India, New Delhi, xxvii+404pp.

Cloudsley-Thompson, J.L. (1992). Ecophysiology of Desert Arthropods and Reptiles. Springer-Verlag, New York, 203pp.

Cloudsley-Thompson, J.L. \& M.J. Chadwick (1964). Life in Deserts. G.T. Foulis Ltd., London, 218pp.

Cunningham, P.L. (2001). Notes on the diet, survival rate, and burrow specifics of Uromastyx aegyptius microlepis from the United Arab Emirates. Asiatic Herpetological Research 9: 30-33.

Das, I. (2002). A Photographic Guide to Snakes and Other Reptiles of India. New Holland (UK) Publishers Ltd., London, 144pp.

Daniel, J.C. (2002). The Book of Indian Reptiles and Amphibians. Bombay Natural History Society \& Oxford University Press, Mumbai, $238 p p$.

Das, S.K. \& V.K. Pandey (2005). Food, feeding, behavior and habitat preferences of Spiny-tailed Lizard (Uromastix hardwicki Gray, 1827) in the Thar Desert of Rajasthan, India. Tigerpaper 32(4): 30-32.

Dutta, S. \& Y. Jhala (2007). Ecological aspects of Indian spiny-tailed lizard Uromastyx hardwickii in Kutch. Journal of the Bombay Natural History Society 104(3): 255-265.

Henderson, P.A. (2003). Practical Methods in Ecology. Blackwell Science Ltd., Oxford, United Kingdom, London, viii+163pp.

Kevork, K. \& H.S. Al-Uthman (1972). Ecological observations on the Egyptian spiny-tailed lizard Uromastyx aegyptius. Bulletin of the Iraq Natural History Museum 5(2): 26-44.

King, G. (1996). Reptiles and Herbivory. Chapman \& Hall, United Kingdom, London, vii+160pp.

Khan, M.Z. \& N. Mahmood (2004). Population status and natural history of agamid lizards of Karachi. Pakistan Journal of Biological Sciences 7(11): 1942-1945.

Knapp, A. (2004). An Assessment of the International Trade in Spinytailed Lizards Uromastyx with a Focus on the Role of the European Union (Technical Report to the European Commission). TRAFFIC Europe, European Commission, Brussels, Belgium, 29pp.

Krishna, D. (1955). Extension Lecture on Deserts and its Animals. University of Rajasthan, Jaipur, India, 20pp.

Krishna, D. \& K.C. Dave (1956). Observations on food and feeding habits of Uromastix hardwickii. Proceedings of $43^{\text {rd }}$ Session of Indian Science Congress, 4: 35.

Ludwig, J.A. \& J.F. Reynolds (1988). Statistical Ecology: A Premier on Methods and Computing. Wiley-Interscience Publication, New York, 337pp.

Mayhew, W.W. (1968). Biology of desert amphibians and reptiles, pp. 196-356. In: Brown, G.W. Jr. (eds.). Desert Biology, Volume-I. Academic Press, New York, 635pp.

Minton, S.A. (1966). A contribution to the herpetology of West Pakistan. Bulletin of the American Museum of Natural History 134(2): 91.

Molur, S. \& S. Walker (eds.) (1998). Report of the Workshop 'Conservation Assessment and Management Plan for Reptiles of India' (BCCP-Endangered Species Project). Conservation Breeding Specialist Group, Zoo Outreach Organisation, Coimbatore, India, $156 p p$.

Pandav, B. \& B.C. Choudhary (1996). Diurnal and sexual activity patterns of water monitor (Varanus salvator) in the Bhitarkanika Mangroves, Orissa, India. Hamadryad 21: 4-12.

Pardeshi, M., V. VijayKumar, N. Gajera \& A. Kumar (2008). Hardwick's Spiny-tailed Lizard (Uromastyx hardwickii, Grey, 1827) preyed on by Indian Sand Boa (Eryx johnii, Russell, 1801). Journal of the Bombay Natural History Society 105(3): 343-344.

Pianka, E.R. (1986). Ecology and Natural History of Desert Lizards. Princeton University Press, New York, 208pp.

Pope, C.H. (1955). The Reptile World. Knopf, New York, xxv+325pp.

Pradhan, S. (1971). A voracious locust predator. Entomologists News Letter 1(1): 5.

Pradhan, S., K.M. Singh, H.S. Sangwan, R.N. Singh \& R.P. Singh (1973). Exploration of vertebrate predators for crop pests-1: food and feeding habits of spiny-tailed lizard, Uromastix sp. Indian Journal of Entomology 35(2): 148-149.

Purves, E.H. (1915). The Thorny-tailed Lizard. Journal of the Bombay 
Natural History Society 23: 780-785.

Ramesh, M. (2008). Final Report 'Status Survey of the Indian Spiny-tailed Lizard Uromastyx hardwickii in the Arid Regions of Rajasthan, North-Westewrn India'. Rufford Small Grants Foundation, 5pp. <www.ruffordsmallgrants.org>. On-line version dated 15 June 2010.

Rodgers, W.A., H.S. Panwar \& V.B. Mathur (2002). Wildlife Protected Area Network in India: A Review (Executive Summary). Wildlife Institute of India, Dehradun, 36pp.

Schmidt, K.P. \& R.F. Inger (1957). Living Reptiles of the World. Doubleday \& Co, New York, 287pp.

Schmidt-Nielsen, K. (2002). Animal Physiology: Adaptation and Environment. Cambridge University Press, ix+613pp.

Sharma, R.C. \& T.G. Vazirani (1977). Food and feeding habits of some reptiles of Rajasthan. Records of the Zoological Survey of India 73: 77-93.

Sharma, R.C. (2002). The Fauna of India and Adjacent Countries, Reptilia-Sauria, Volume-II. Zoological Survey of India, Kolkata, xxv+430pp.

Smith, M.A. (1935). The Fauna of British India, Including Ceylon and Burma: Reptilia and Amphibia-Sauria, Volume-II. Taylor \& Francis, London, xiii+440pp.

Vogt, R.C. \& R.L. Hine (1982). Evaluation of techniques for assessment of amphibian and reptile population in Wisconsin, pp. 201-217. In: Scott, N.J. Jr. (eds.). Herpetological Communities. Wildlife Research Report No-13, U.S. Department of the Interior, Fish \& Wildlife Service, Washington D.C., iv+239pp.

Wilms, T.M., W. Bhome, P. Wagner, N. Lutzmann \& A. Schmitz (2009a). On the phylogeny and taxonomy of the genus Uromastyx Merrem, 1820 (Reptilia: Squamata: Agamidae: Uromastycinae): Resurrection of the Genus Saara Gray, 1845. Bonner Zoologische Beiträge 56(1/2): 55-99.

Wilms, T.M., P. Wagner, M. Shobrak \& W. Bhome (2009b). Activity profiles, habitat selection and seasonality of body weight in a population of Arabian Spiny-tailed Lizards (Uromastyx aegyptia microlepis Blanford, 1875; Sauria: Agamidae) in Saudi Arabia. Bonner Zoologische Beiträge 56(4): 259-272.

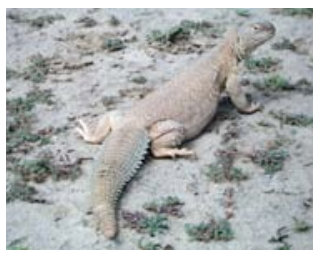

Video 1. Adult Spiny-tailed Lizard foraging
Author Details: SANJAY K. DAS is working as Assistant Professor at Guru Gobind Singh Indraprastha University, Delhi. He is actively engaged with research work on taxonomy, ecology and conservation of herpetofauna of the Indian subcontinent. SUMIT DookIA is also working as Assistant Professor at GGS Indraprastha University, Delhi. His research contribution is on mammals and birds of this region. KALPANA DAS at present is pursuing her research work on herpetofauna of this region at Centre for Ecological Sciences, Indian Institute of Science, Bengaluru after completing her M.Sc in Biodiversity \& Conservation from Guru Gobind Singh Indraprastha University, Delhi. SUSHIL K. DUTTA is working as Visiting Professor at Centre for Ecological Sciences, Indian Institute of Science, Bengaluru and is one of the renowned herpetologists and actively engaged in biosystematics studies of herpetofauna of the Indian subcontinent since last three decades. 